\title{
Intraoperative Complication Management and Prevention
}

National Cancer Institute

\section{Source}

National Cancer Institute. Intraoperative Complication Management and Prevention. NCI

Thesaurus. Code C116687.

Any action taken during surgery whose purpose is to mitigate and/or prevent the occurrence of an undesirable outcome. 